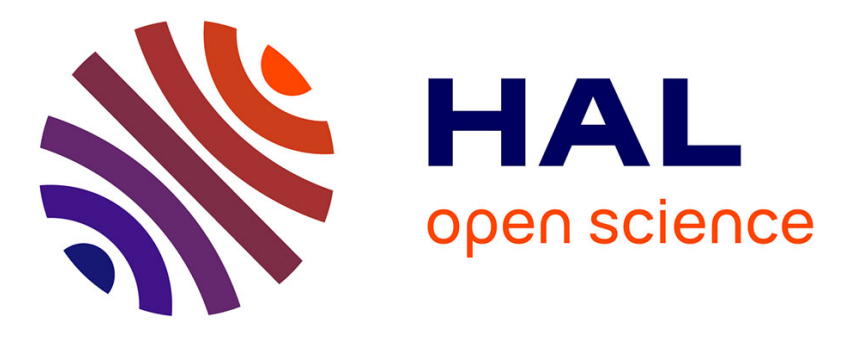

\title{
Conserved and specific functions of axoneme components in trypanosome motility.
}

Carole Branche, Linda Kohl, Géraldine Toutirais, Johanna Buisson, Jacky Cosson, Philippe Bastin

\section{- To cite this version:}

Carole Branche, Linda Kohl, Géraldine Toutirais, Johanna Buisson, Jacky Cosson, et al.. Conserved and specific functions of axoneme components in trypanosome motility.. Journal of Cell Science, 2006, 119 (Pt 16), pp.3443-55. 10.1242/jcs.03078 . hal-00108209

\section{HAL Id: hal-00108209 \\ https://hal.science/hal-00108209}

Submitted on 19 Oct 2006

HAL is a multi-disciplinary open access archive for the deposit and dissemination of scientific research documents, whether they are published or not. The documents may come from teaching and research institutions in France or abroad, or from public or private research centers.
L'archive ouverte pluridisciplinaire HAL, est destinée au dépôt et à la diffusion de documents scientifiques de niveau recherche, publiés ou non, émanant des établissements d'enseignement et de recherche français ou étrangers, des laboratoires publics ou privés. 


\section{Conserved and specific functions of axoneme components in trypanosome motility}

Carole Branche $^{1 *}$, Linda Kohl², Géraldine Toutirais ${ }^{1}$, Johanna Buisson ${ }^{1}$, Jacky Cosson ${ }^{3}$ and Philippe Bastin ${ }^{1 *}$

${ }^{1}$ INSERM U565 \& CNRS UMR5153 \& MNHN USM0503, Muséum National d'Histoire Naturelle, 43 rue Cuvier, 75231 Paris cedex 05, France

2USM0504, Muséum National d'Histoire Naturelle, 61 rue Buffon, 75231 Paris cedex 05, France

${ }^{3}$ CNRS UMR7009, Station zoologique, BP28, 06230 Villefranche sur Mer, France

To whom correspondence should be addressed. E-mail: pbastin@pasteur.fr

*Present address: Trypanosome Cell Biology Unit \& CNRS URA 2581, The Pasteur Institute, 25, rue du Docteur Roux, 75724 Paris cedex 15, France.

Running title: Trypanosome flagellum and motility

Key words: flagellum, axoneme, central pair, motility, trypanosome, paraflagellar rod (7,993 words) 


\section{Summary}

The Trypanosoma brucei flagellum is unusual as it is attached along the cell body and it contains in addition to an apparently conventional axoneme, a structure called the paraflagellar rod (PFR) that is essential for cell motility. Here, we investigated flagellum behaviour in normal and mutant trypanosome cell lines where expression of genes encoding various axoneme proteins (PF16, PF20, DNAI1, LC2) had been silenced by RNAi. First, we show that the propulsive wave (normally used for forward motility) is abolished in the absence of outer dynein arms whilst the reverse wave (normally used for changing direction)

still occurs. Second, in contrast to Chlamydomonas but like metazoa, the central pair adopts a fixed orientation during flagellum beating. This orientation becomes highly variable in central pair and outer dynein arm mutants. Third, the PFR contributes to motility by facilitating three-dimensional wave propagation and controlling cell shape. Fourth, motility is required to complete the last stage of cell division in both insect and bloodstream stages of the parasite. Finally, our study also reveal the conservation of molecular components of the trypanosome flagellum. Coupled to the ease of reverse genetics, it raises the interest of trypanosomes as model organisms to study cilia and flagella. 


\section{Introduction}

Cilia and flagella are ancient cellular organelles encountered from protists to mammals. They are often motile and as such involved in cell propulsion or in movement of the surrounding environment. Defects in cilia construction or function are responsible for various genetic diseases such as primary ciliary dyskinesia, polycystic kidney disease, retinitis pigmentosa or the Bardet-Biedl syndrome (Eley et al., 2005; Pan et al., 2005). The basic architecture of cilia and flagella is the axoneme, that is remarkably conserved during evolution (Silflow and Lefebvre, 2001). This cylindrical structure is made of nine doublets of peripheral microtubules, with $(9+2)$ or without $(9+0)$ a central pair of single microtubules. The axoneme extends from the basal body, an organelle equivalent to the centriole (Beisson and Wright, 2003). Defined substructures are associated to the majority of motile 9+2 axonemes: the central pair microtubules carry specific projections whereas peripheral microtubules bear inner and outer dynein arms, radial spokes and nexin links. Dyneins are molecular motors and their action generates the force that causes adjacent microtubule doublets to slide past one another (Brokaw, 1972). Since the doublets are tethered to the cell via the basal body and attached to each other by nexin links, this sliding is translated into flagellar bending. However, to generate the complex waveforms observed in numerous cilia and flagella, a precise coordination of dynein action is required. Indeed, the axoneme is a symmetric structure and if all dynein arms were active simultaneously, it would result in a rigid rigor-like state. The central pair apparatus displays specific associated projections and is structurally and biochemically asymmetric (Mitchell, 2003b). It could therefore act as a regulator of dynein activity, for example by transmitting signals via radial spokes (Smith and Sale, 1992). In agreement with this model, mutations affecting central pair presence, structure 
or components all have drastic consequences on axoneme movement (Sapiro et al., 2002; Smith and Lefebvre, 1996; Smith and Lefebvre, 1997; Tamalet et al., 2001). The existence of a dynein regulating complex has been proposed (Piperno et al., 1992) and one of its molecular component was recently identified (Hutchings et al., 2002; Rupp and Porter, 2003).

In Paramecium and in the green alga Chlamydomonas, the central pair twists during flagellum bending in such a way that it is found parallel to the bend plane in curved areas and perpendicular in straight segments (Mitchell, 2003a; Omoto and Kung, 1979). This led to the suggestion that rotation of the central pair would define which dynein arm should be active, a proposal supported by the fact that the $\mathrm{C} 1$ microtubule is predominantly orientated towards the position of active dynein in re-activated axonemes of Chlamydomonas (Wargo and Smith, 2003). In contrast, in the flagellum of sea urchin sperm and in cilia of other metazoa, the orientation of the central pair appears fixed and perpendicular to the bend plane (Sale, 1986; Tamm and Tamm, 1981). Nevertheless, these flagella are also actively beating, raising the question of how the central pair could regulate their motility. Unfortunately, reverse and forward genetics are limited in these organisms, which restricts detailed functional analysis.

Trypanosoma brucei is a flagellated protozoan responsible for sleeping sickness in Africa. The parasite alternates between the bloodstream of a mammalian host and several tissues of its insect vector, the tsetse fly. All life cycle stages are flagellated. The single flagellum emerges from an invagination of the cell body called the flagellar pocket, which is also the unique site for endo- or exocytosis (Gull, 2003). The flagellum is tethered along the cell body with the exception of its distal tip. It is made of a classic $9+2$ axoneme with dynein arms and radial spokes but exhibits an original additional structure, the paraflagellar rod (PFR) (reviewed in (Bastin et al., 1996; Maga and LeBowitz, 1999)). The PFR has a diameter similar to that of the axoneme and is anchored via connection to doublets 4 to 7 of the latter. Intriguingly, RNAi silencing of PFR main components led to strong reduction in flagellum 
beating and cell paralysis, despite the presence of an apparently normal axoneme structure (Bastin et al., 1998; Durand-Dubief et al., 2003). Motility was significantly reduced (although not abolished) after knock-out of the corresponding genes in the related parasite Leishmania mexicana, whose flagellum is free from most of the cell body (Maga et al., 1999; Santrich et al., 1997). In addition to cell motility, the T. brucei flagellum is intimately linked to cell morphogenesis (Kohl et al., 2003). Genome comparison revealed that most genes involved in construction and function of the axoneme are conserved in trypanosomes (Berriman et al., 2005; Briggs et al., 2004; Kohl and Bastin, 2005). In contrast to many flagellated cell types, trypanosomes can easily be grown and transformed in culture, what makes them an attractive model for functional analysis of flagellum.

In this article, we investigated the importance of the axoneme in flagellum and cell motility of T. brucei by comparing control cells with RNAi mutants of various axoneme components. We describe the unusual beating of the flagellum which produces two waveforms: a principal one that propagates from tip to base and a reverse one which propagates from base to tip and allows the cell to change direction. Ultra-structural analysis revealed that the central pair bears multiple projections and keeps a fixed position in wild type flagella while it becomes highly variable in mutants of the central pair or of outer dynein arms. The contribution of the PFR was re-examined and finally, this study demonstrated the role of flagellum motility in completing cell separation in both insect and bloodstream stages. 


\section{Material and methods}

\section{Trypanosome cell lines and culture}

T. brucei cells at the procyclic stage (corresponding to parasites developing in the midgut of the tsetse fly) were cultured at $27^{\circ} \mathrm{C}$ in semi-defined medium 79 containing $10 \%$ foetal calf serum and hemin. Wild-type (strain 427), 29-13 (Wirtz et al., 1999) and derivatives, snl-2 (Bastin et al., 2000) and PFRAi (Durand-Dubief et al., 2003) cell lines were used. For induction of RNAi, cells were grown in the presence of $1 \mu \mathrm{g}$ of fresh tetracycline per $\mathrm{ml}$ of culture medium. Culture density was maintained between 1 and 10 millions cells per $\mathrm{ml}$ by regular dilution and growth curves were presented as cumulative data, allowing global view for long-term experiments. In the case of bloodstream trypanosomes, the cell line 90-13 (Wirtz et al., 1999) was grown in HMI-9 medium with $10 \%$ foetal calf serum as described (Hirumi and Hirumi, 1989).

\section{Identification of axoneme genes}

The T. brucei GeneDB database (http://www.genedb.org/genedb/tryp/blast.jsp) was screened by BLAST search using known axoneme genes. Genes encoding a putative dynein heavy chain (Tb10.70.1720), the dynein light chain LC2 (Tb11.02.5620), the central pair proteins PF16 (Tb927.1.2670) and PF20 (Tb10.61.2920), and the radial spoke protein RSP3 (Tb11.47.0034) were identified using Chlamydomonas sequences. The TbDNAII (Tb11.02.2640) gene was identified by BLAST search using the human gene (NP036276). Protein sequences were aligned using MegAlign package from DNASTAR software (Lasergene). 


\section{Plasmid construction and RNAi mutant cell line generation}

Primers were designed to PCR-amplify fragments of genes from wild-type T. brucei genomic DNA. Forward and reverse primer sequences were, for PF16, 5'-CGATGAATTC

CTCGAGTTGA TGCCTTGCAG CAGGCC-3’ and

5'-CGATCGAAGCTTAGACAATGACAGCGAGAGCG-3', for PF20, 5'GAGACTCGAGTCATCGAGCCAACCATAACC-3' and

5'-AGAGAAGCTTCCTGACATCACAAGTTCGCC-3', for RSP3, 5'-

CGACCGAAGCTTATGCAAGGGCAAAACCAAGC-3' and 5'-

CGACCAGATCTCTACTTGGCGAATGAGATC-3', for LC2,

5'-CGATGAATTCCTCGAGATGG TGAACGAGTA CCATG-3' and

5'-CGATCGAAGCTTCTACTCCCAGTACAGCGC-3', for DNAI1,

5'-GAGACTCGAGACAAGGTGAAACATCGTGCC-3' and

5'-AGAGAAGCTTCAGGATCGAAGACACATGCG-3', for DNAH,

5'-GAGACTCGAGCCACGGATGGAAGTGATGAG-3' and

5'-AGAGAAGCTTGGAGGAGTTTCGGCGTATTC-3'. PCR products were purified and cloned in the pZJM vector (Wang et al., 2000). After electroporation, cells that had integrated the plasmid were selected for three weeks in culture medium containing $20 \%$ foetal calf serum and the appropriate antibiotics $(15 \mu \mathrm{g} / \mathrm{ml} \mathrm{G} 418,20 \mu \mathrm{g} / \mathrm{ml}$ hygromycin, $2 \mu \mathrm{g} / \mathrm{ml}$ phleomycin). For analysis, 5-20 transformed cell lines were induced and characterised, and one was selected for sub-cloning by limiting dilution (Bastin et al., 1999a).

Transient transfection of double-stranded (ds) RNA (Ngô et al., 1998) in bloodstream trypanosomes was performed with in vitro synthesised PFR2 or GFP dsRNA (Durand-Dubief and Bastin, 2003). Transfected cells were returned to culture, incubated for 5 to 20 hours in normal culture medium and analysed by video microscopy or fixed and processed for immunofluorescence with the anti-PFR2 monoclonal antibody L8C4. 


\section{Electron microscopy}

Cells were washed in $0.1 \mathrm{M}$ cacodylate buffer $(\mathrm{pH} 7.2)$ and fixed in $2.5 \%$ glutaraldehyde, $2 \%$ paraformaldehyde, $0.5 \%$ tannic acid solution for two hours at room temperature. Fixed samples were washed three times in $0.1 \mathrm{M}$ cacodylate buffer (pH 7.2) and post fixed in 1\% osmium- 0.1 M cacodylate solution ( $\mathrm{pH}$ 7.2) for two hours in the dark under agitation. Samples were stained en block with a $2 \%$ aqueous uranyl solution at $4{ }^{\circ} \mathrm{C}$ overnight, were gradually dehydrated in ethanol and finally embedded in Spurr resin followed by polymerisation for three days at $70^{\circ} \mathrm{C}$.

For detergent-extraction of flagella (that facilitates observation of axoneme ultrastructure (Witman et al., 1978)), cells were treated with PEM (100 mM Pipes-2 mM EGTA- 1 $\mathrm{mM} \mathrm{MgSO}_{4}$ ) -1\% Nonidet P40 solution for 10 min (Sherwin and Gull, 1989). Washed samples were fixed in $2.5 \%$ glutaraldehyde- $0.5 \%$, tannic acid solution for two hours at room temperature and processed as described above. $60 \mathrm{~nm}$ thick sections were cut with a ultracut E REICHERT microtome and picked up on copper/rhodium coated grids. They were viewed using a Hitachi 7100 TEM and images were captured with Hamamatsu C4742-95 digital camera. Images were analysed with Image J software (NIH, USA).

\section{Antibodies and immunofluorescence}

Cells were spread on poly-L-lysine coated slides and fixed in methanol at $-20^{\circ} \mathrm{C}$ before processing as described (Sherwin et al., 1987). Indirect immunofluorescence was performed with the anti-PFR2 specific monoclonal antibody L8C4 (Kohl et al., 1999). DNA was stained with DAPI. Slides were viewed using a DMR Leica microscope and images were captured with a Cool Snap HQ camera (Roper Scientific). Images were analysed using the IPLab Spectrum software (Scanalytics). 


\section{Motility analysis}

After induction of RNAi for the indicated periods, cell motility was analysed by videomicroscopy (individual cell analysis) using differential interfering contrast or dark field microscopy. Beat frequency of individual flagella was measured using stroboscopic illumination (details below). Beat frequency was evaluated on individual cells by adjustment of the flash frequency with the beat frequency of the distal portion of the flagellum (terminal 5 to $10 \mu \mathrm{m}$ of the flagellum). Cells were observed with an Olympus BH2 microscope equipped with dry (Zeiss $25 \mathrm{X})$ or oil immersion lenses. In the latter case, the objective lenses used were either an Olympus 40X D-Apo UV-oil 1.30 with diaphragm or a Reichert 100X Plan-oil 1.25 with iris, combined with an Olympus Dark Field oil condenser DWC 1.4-1.2. Records were obtained using stroboscopic illumination by a Strobex (Chadwick-Helmuth, El Monte, CA, USA). Video images were recorded with a Panasonic WV- F 15 E S-VHS video camera (constant frame rate of the European standard, $50 \mathrm{~Hz}$ ) connected to a Hamamatsu video image processor (DVS 3000) and to a Panasonic AG 7330 S-VHS video recorder synchronized to the stroboscopic illumination with a fiber optic "video-sync" (module \#9630, ChadwickHelmuth). The S-VHS video tapes were digitalised by use of a Formac DV digitaliser connected to an Apple iBook G4. Montage of the Quick Time movies was obtained with the iMovie software. Interfering with flagellum motility reduces cell mobility and as a consequence cells stop swimming and sediment at the bottom of the culture flask, a factor that can be monitored in sedimentation assays (Bastin et al., 1999b). 


\section{Results}

\section{Structural arrangement of the trypanosome flagellum}

Most typical sub-structures present in classic $9+2$ axonemes are visible in crosssections of the T. brucei flagellum: a central pair and associated projections, radial spokes, nexin links, inner and outer dynein arms (Fig. 1A-C)(Sherwin and Gull, 1989; Vickerman, 1962; Vickerman, 1976). To obtain a clearer view of axoneme sub-structures, especially central pair projections, cells were treated with detergent and peripheral and central pair microtubules were numbered as described previously (Sherwin and Gull, 1989). Compared with the canonical view of the Chlamydomonas axoneme, several differences were noted (Fig. 1A-C). First, 9 outer dynein arms were visible in all cross-sections (instead of 8 in green alga flagella). Second, radial spoke heads looked larger. Third, organisation of central pair projections appeared different (Fig. 1A, insert). At least 3 projections were visible on each microtubule but these were not symmetric. The $\mathrm{C} 1$ microtubule carries three electron-dense short projections $(5-10 \mathrm{~nm})$. The $\mathrm{C} 2$ microtubule exhibits two long $(15-20 \mathrm{~nm})$ projections (termed $2 \mathrm{a}$ and $2 \mathrm{~b}$ ) and a short projection. A bridge appears to connect both central microtubules and a kind of sheath could also be detected in some sections. Longitudinal sections revealed several projections (Fig. 1D) but as in other species (Mitchell, 2003b), close proximity of radial spoke heads complicated the interpretation.

The PFR is associated to the axoneme via a thick connection on microtubule B of doublet 7, and thinner filaments to doublets 6 to 4 (Fig. 1A-C) (Hemphill et al., 1991). Double immunofluorescence analysis with antibodies against PFR proteins and tubulin suggested that the PFR is found between the axoneme and the cell body (Woods et al., 1989). Electron microscopy indicated that filaments appear to link the proximal zone of the PFR 
(initiating in the vicinity of doublet 7 of the axoneme) and the FAZ (Flagellum Attachment Zone) filament that runs on the cell body side following the flagellum path (Sherwin and Gull, 1989). The axoneme is often seen in close proximity to the region of the cell body where the four specialised sub-pellicular microtubules are associated to the FAZ filament are visible (Fig. 1B). We wondered how such an edifice could behave during flagellum bending. We therefore analysed cross-sections of wild-type flagella and observed that the most common disposition $(\sim 2 / 3$ of sections, $n=40)$ was with the flagellum lying on its side, with both PFR and axoneme apposed to the region of the cell body with the FAZ filament and the four specialised microtubules respectively (Fig. 1B, left panel). We defined this state as the "side arrangement". Twice less frequent were profiles where only the PFR appeared in close contact with the cell body ("PFR arrangement")(Fig. 1B, right panel). Only in rare instances (1 section out of 40) was the axoneme in closer proximity to the cell body than the PFR. Finally, a few profiles were seen with the flagellum alone, without being in contact to a cell body. These likely correspond to the free distal end of the flagellum.

To determine the orientation of the central pair relative to peripheral microtubules, we used PFR positioning as an unambiguous landmark. Indeed, the PFR is firmly anchored to the axoneme as described above and these connections can only be disrupted by trypsin treatment (Russell et al., 1983). We measured the angle between the axis of the central pair and that of the proximal domain of the PFR in cross-section of wild-type flagella (Fig. 1A). This revealed that the orientation of the central pair is almost invariant in all axoneme crosssections analysed at an angle of -7.0 degrees $\pm 6.5(n=36)$. This orientation was maintained in samples fixed after membrane removal following detergent extraction (angle of -10.3 degrees $\pm 5.3, \mathrm{n}=42$ ). Similar determined orientation has also been observed in the related parasite Leishmania mexicana where the central pair and the PFR appear almost parallel in 80 out of 80 cross-sections examined (M. Wiese, personal communication). In contrast to species with 
planar flagellum wave forms (Mitchell, 2003a), the arrangement of the trypanosome flagellum around the cell body severely restricted the possibility of examining central pair orientation relative to flagellum bending. Nevertheless, some longitudinal sections suggested that the central pair is twisted exactly in the same way as peripheral microtubules, following the arrangement of the trypanosome flagellum around the cell body (data not shown). These data suggest that the central pair of the trypanosome axoneme adopts a fixed orientation relative to the peripheral microtubules, as observed in metazoa.

\section{Identification and RNAi silencing of trypanosome axoneme genes}

To establish the importance of the axoneme in flagellum motility of trypanosomes, we first searched for representative genes encoding axoneme proteins (Fig. 1E). We selected the central pair protein $\mathrm{PF} 16$, an armadillo-containing polypeptide, found on the $\mathrm{C} 1$ microtubule and essential for flagellum motility in Chlamydomonas (Smith and Lefebvre, 1996) and in mouse (Sapiro et al., 2002). As central pair projections appear slightly different in trypanosomes, we selected another representative of this complex, the PF20 protein, rich in WD40 repeats and present on the bridge between the two singlet microtubules (Smith and Lefebvre, 1997). RSP3 was chosen as specific marker of the radial spoke since its invalidation leads to complete spoke disruption (Williams et al., 1989). Dynein arms are multi-subunit structures made of one to three heavy chains that have motor activity and a variable number of intermediate and light chains. The later ones are required for regulation and assembly of the dynein complex but have no intrinsic motor activity (reviewed in (DiBella and King, 2001; Kamiya, 2002)). The intermediate chain protein DNAI1 (IC78) is an essential component of the outer dynein arm (Wilkerson et al., 1995) and was selected as it is the first gene where mutations associated to human ciliary disorders have been identified (Pennarun et al., 1999). For the light chain, we selected LC2 (TcTex2), whose mutations are responsible for genetic 
distortion in mouse (Pazour et al., 1999). We mined the genome databases of T. brucei and of the related parasites Leishmania major and Trypanosoma cruzi and were able to find orthologues of each axoneme gene in all three species. In T. brucei, only one corresponding gene of each was found with the exception of heavy dynein chains where a total of 12 members were identified. One gene encodes the conventional cytoplasmic dynein and two separate ones present the signature of dynein heavy chains involved in retrograde intraflagellar transport (Kohl and Bastin, 2005). Both latter genes are essential for flagellum assembly (Kohl et al., 2003)(Absalon and Bastin, unpublished). At the time this project was launched, only one axonemal dynein heavy chain gene was fully sequenced and this one was selected for further studies. Sequence alignments and analysis suggests that this protein would belong to the inner dynein arm group, with closest homologues being the human dynein heavy chain 1 or the sea urchin heavy chain 6 .

Alignments of T. brucei predicted axoneme proteins with orthologues of Chlamydomonas, mouse and human show a significant conservation degree (Fig. 1E). Percentage of identity ranged around 30-40\% between human and trypanosomes, with the exception of PF16 that largely exceeds $60 \%$ of identity. These values are in the same range as between Chlamydomonas and human flagellar genes (Pennarun et al., 1999; Sapiro et al., 2000). In contrast, the PFR genes, initially identified in T. brucei (Deflorin et al., 1994; Schlaeppi et al., 1989), are exclusively present in Trypanosomatid and Euglenid genomes so far with no counterpart in other species (Kohl and Bastin, 2005).

To determine the role of the axoneme in flagellum motility of T. brucei, we silenced expression of the above genes by inducible RNAi. A fragment of each gene was amplified by PCR from genomic DNA and cloned in an expression vector allowing inducible expression of dsRNA (Wang et al., 2000). These plasmids were stably transformed and RNAi was triggered by addition of tetracycline that switches on expression of dsRNA. The extent of RNAi 
silencing was evaluated by RT-PCR (Durand-Dubief et al., 2003) using mRNA for aldolase as a control (Fig. S1). This confirmed silencing at the RNA level for all cell lines after 2 or 3 days of induction with the exception of (TbDNAH) where mRNA amounts were poorly or not affected. Upon RNAi silencing, examination of almost all live cell lines by light microscopy revealed variable reduction in motility as early as 24 hours after addition of tetracycline in the (TbPF16)RNAi cell line and 48 hours for the other mutants with the exception of (TbDNAH) RNAi that showed no difference compared to controls, as expected from the RT-PCR data. An important parameter needs to be taken into account for correct interpretation: RNAi targets RNA and not protein. Hence proteins present in flagella assembled before the onset of RNAi will remain present and only disappear according to their rate of turn-over. Typically, in the case of silencing of flagellar genes, a protein can be missing in the new flagellum but still be present in the old flagellum (Bastin et al., 2000; Kohl et al., 2003; McKean et al., 2003).

\section{Motility analysis}

Motility phenotypes were further characterised at the individual cell level by videomicroscopy (Movies 1-4 see Supplementary Material) and at the population level by sedimentation assays (Fig. 2). The flagellum of trypanosomes from wild-type, 29-13, noninduced RNAi cell lines or a control induced RNAi cell line silencing a gene not involved in motility (called F6) beats normally and cells swim with their flagellum leading (Movie 1). The principal flagellar wave travels from tip to base and is responsible for forward cell propulsion. The distal end of the flagellum beats at a frequency of $12-14 \mathrm{~Hz}(\mathrm{n}=83$, measured on 3 separate non-induced samples), with no significant differences between cells in motion and cells attached to the slide. The amplitude of the wave is constant as it is transmitted along the free part of the flagellum and the anterior end of the cell but is reduced progressively as it nears the base of the organelle which is embedded in the cell body. This intimate association 
with the cell body likely contributes to weaken both wave amplitude and frequency, and also prevented precise measurements of these parameters at the proximal end. At variable time intervals, the flagellum switches for short periods to a base to tip wave propagation, whose beat frequency is $3-5 \mathrm{~Hz}$ (Movie 1). The amplitude was wider compared to what was observed for the principal wave. This switch lead to profound re-orientation of the anterior end and then of the whole cell without obvious backward motility.

(TbPF16)RNAi cells induced for 2 days looked paralysed and sedimented at the bottom of the flask (Movie 2/Fig. 2). The flagellum frequently appeared to be partially detached from the main cell body in $\sim 30 \%$ of the cells $(n=322)$. The second cell shown on the movie possesses two flagella. Whereas the old one is still motile, the new one is paralysed and partially detached from the cell body. The amplitude and the frequency of the propulsive wave were strongly reduced and often abolished. The reverse wave occurred less frequently but was occasionally visible. The other central pair mutant, (TbPF20)RNAi displayed a similar phenotype, although less intense (Fig. 2 and data not shown). (TbRSP3)RNAi mutants also presented significant alterations in motility (data not shown). As this mutant is being studied intensively elsewhere (K. Hill, personal communication), we have not performed further investigation. (TbDNAH)RNAi did not show significant modifications of swimming pattern and behaved like to wild-type or non-induced cells (not shown). In contrast, (TbDNAI1)RNAi cells stop swimming and their flagella exhibited interesting features (Movie 3/Fig. 2). The propulsive wave was absent, however the reverse wave was still active and maintained continuously the 3-5 Hz beat frequency $(\mathrm{n}=38)$ (Movie 5). This indicates a central role for TbDNAI1 in the tip-to-base flagellum movement. Finally, we reexamined motility of a trypanosome mutant deprived of most of the PFR structure after PFR2 RNAi silencing (Movie 4/Fig. 2). The sedimentation assay reproduced previous experiments (Bastin et al., 1999b; Durand-Dubief et al., 2003) as expected. However, video-microscopy 
highlighted an intriguing characteristic: instead of the classic twisted cell body shape, $>90 \%$ of the cells looked bent at approximately right angle (Movie 4). Interestingly, the distal tip of the flagellum is still motile, sometimes displaying a normal beat amplitude at the free distal end where movements appear mostly planar. This was poorly or not transmitted to the cell body that appeared rigid. In addition, the flagellum rapidly oscillated between principal and reverse waves, resulting in the absence of cell propulsion.

\section{Ultra-structural defects of the axoneme}

We next examined axoneme ultra-structure in the various mutants by transmission electron microscopy three days after induction of RNAi (Fig. 3 \& Fig. S2). First, we looked at the disposition of the flagellum relative to the cell body. In both central pair mutants, a drop in the proportion of cells with the "side arrangement" was observed: only $35 \%$ of crosssections in (TbPF16)RNAi mutants $(\mathrm{n}=87)$ and $30 \%$ in (TbPF20)RNAi mutants $(\mathrm{n}=21)$ instead of $66 \%$ in controls. In the case of (TbPF20)RNAi cells, this was accompanied by an increase in the proportion of "PFR arrangements" (60\% profiles) and a slight increase in flagella without cell body ( 10\%). For (TbPF16)RNAi cells, $35.6 \%$ of cross-sections through flagella were seen without a cell body, in good agreement with the frequency of cells with a detached flagellum (30\%). These data suggest that the "side arrangement" of the flagellum could be linked to flagellum motility.

The central pair microtubules are destabilised in sperm flagella of PF16 mouse knockout mutants (Zhang et al., 2002). About $20 \%$ of flagella profiles of (TbPF16)RNAi and (TbPF20)RNAi mutants induced for 3 days present only one central microtubule, with a few without central pair at all (Fig. 3A,Table 1). It should be noted that the majority (12 out of 15) of these sections are likely to be close to the distal tip of the flagellum as they were seen near the narrow anterior end of the cell, or without the cell body at proximity. Both central 
pair microtubules were visible in all other examined mutants. To gain more precise insights on structural defects of the axoneme, the flagellum membrane was removed by treatment with Nonidet P-40. The buffer used did not contain sodium chloride and stability of central pair microtubules was not modified compared to non-extracted samples, as observed for Chlamydomonas $\{$ Mitchell, 1999 \#92\}. However, several projections were frequently missing, indicating defects in central pair organisation. Another unexpected modification was apparent: at least one outer dynein arm was absent, usually on doublet 5 in the case of (TbPF20)RNAi and on doublets 5 and 6 for (TbPF16)RNAi (Table 2). This was not a consequence of detergent extraction as a similar proportion of flagella missing at least one outer dynein arm was found on images of fixed intact cells (Table 2). This defect was never observed on sections of wild type cells $(n=70)$. In contrast, inner dynein arms did not appear modified.

Observation of (TbDNAI1)RNAi flagella cross-section (Fig. 3B/Table 2) demonstrated the importance of DNAI1 for outer dynein arm assembly: out of 46 profiles analysed, 32 missed all 9 dynein arm complexes and 13 missed at least one of them. However, neither inner dynein arms nor the central pair microtubules displayed structural problems. These data demonstrate that DNAI1 is essential for outer dynein arm assembly in trypanosomes as it is the case in Chlamydomonas and humans.

The orientation of the central pair was examined in (TbPF16)RNAi, (TbPF20)RNAi and (TbDNAI1)RNAi mutants. Whereas the central pair was at a determined slightly negative angle relative to the PFR in wild-type flagella, its orientation appeared highly variable in all three mutants, with a wide dispersion over at least 180 degrees (Fig. 3D). Whereas only $10 \%$ of sections through wild-type flagella $(\mathrm{n}=82)$ showed an angle superior to \pm 15 degrees, this value raised to $65 \%$ for (TbPF20)RNAi ( $n=65), 46 \%$ for (TbPF16)RNAi $(n=116)$ and $62 \%$ for (TbDNAII1)RNAi ( $\mathrm{n}=44)$. It was difficult to unambiguously distinguish the $\mathrm{C} 1$ from the 
$\mathrm{C} 2$ microtubule in these images, especially in central pair mutants where projections were modified, so these values are likely to be underestimates as variations up to 360 degrees cannot be ruled out. This dispersion was also found in detergent-extracted cells for all three mutant cell lines (Fig.3C,D). Nevertheless, about half of the sections in flagella of mutant cell lines still presented an almost parallel orientation to the PFR. These could represent completely twisted central pairs (plus or minus 180 degrees) or correspond to cells where RNAi silencing is not complete. Ultra-structural analysis of the (TbDNAI1)RNAi mutant revealed that $\sim 85 \%$ of cells lacked most of the dynein arms, indication that the remaining 15 $\%$ could correspond to cells behaving close to controls. Due to the short size of profiles seen in longitudinal section, it was not possible to determine whether the central pair was fixed at a particular angle along the length of a given flagellum or whether it was rotating within the same axoneme. A few longitudinal sections in the (TbPF16)RNAi mutant strain suggested that the central pair maintains a fixed orientation (parallel to the bend plane) during flagellum bending (Fig.3C). In contrast, analysis of flagella of paralysed PFR mutants showed that central pair orientation remains similar to wild-type (Bastin et al., 1998)(data not shown). These data show that defects of central pair or outer dynein arm result in loss of the fixed central pair orientation.

\section{Flagellum motility is required for septation}

Upon induction of RNAi silencing targeting TbPF16 or TbPF20, or to a lesser extent TbDNAI1, we noticed a reduction in the growth rate (Fig. 4) and an accumulation of large cellular aggregates in the culture flasks, suggesting cell separation defects. Examination of dividing wild-type or non-induced trypanosomes revealed that daughter cells are only joined by their posterior end, with their flagella beating in opposite directions. Due to the flagellum arrangement on the cell body, both cells tend to twist in opposite direction, what could 
contribute to exert tension on the mid-body and participate to cell separation (Fig. 5A/Movie 5). Examination of (TbPF16)RNAi cells at early stages of induction (24-48 hours) revealed that numerous bi-flagellated cells possess a motile flagellum (the old one) and an immotile flagellum (the new one). Strikingly, when cells are about to divide, the progeny carrying the old flagellum is motile and drags its immotile counterpart behind it, indicating that motility could indeed contribute to cell separation (Fig. 5B/Movie 6). At later stages of induction (4872 hours), both flagella are paralysed and progression through cytokinesis appears much slower (Fig. 5C/Movie 7), what could explain the slow growth phenotype observed (Fig. 4). Similar results were observed for (TbPF20)RNAi and to a lesser extent for (TbDNAI1)RNAi, whereas induced cell lines with weaker motility phenotypes such as (TbLC2)RNAi that displayed jerky but active movements (data not shown) and (TbDNAH)RNAi that behaved essentially as wild-type (Fig. 4). Despite showing significant reduction in motility, snl-2 or (PFR2)RNAi mutants showed little cytokinesis defects and grew almost as fast as wild-type and non-induced controls (Fig. 4) (Bastin et al., 1999b; Bastin et al., 1998). Observation of dividing induced snl-2 trypanosomes indicated that daughter cells are still able to twist whilst attached (Movie 8), a feature not seen in induced (TbPF16)RNAi or (TbPF20)RNAi. This motility might be sufficient to severe the mid-body and allow cytokinesis completion. If this is exclusively dependent on mechanical shearing force, we reasoned that shaking the culture could compensate this defect. We therefore cultivated non-induced and induced cell lines with or without agitation and compared their growth rate (Fig. 5D, 4). Shaking the culture lead to a spectacular reduction in the number of cell aggregates for all cell lines examined, confirming that mechanic force can compensate for the cell division defect (Fig. 5D). But this failed to restore normal cell growth, indicating that other parameters should be altered. Detailed cell biology revealed that these cells had difficulties in segregating their basal bodies, a key stage of the trypanosome cell cycle (unpublished data). An alternative explanation is 
that cells cannot feed properly, due to defects in endocytosis that solely takes place at the level of the flagellar pocket. This is clearly not the case as the endocytic network of cells from unshaken cultures of(TbPF16)RNAi mutants is not modified compared to controls (Fig. S2).

We also investigated the consequences of reduced motility in bloodstream form trypanosomes. Cells were transfected with double-stranded RNA corresponding to the PFR2 gene or to the GFP gene as control. Consequences of RNAi silencing were monitored by immunofluorescence with a specific anti-PFR2 monoclonal antibody (Kohl et al., 1999). At early time points (5-8 hours), numerous biflagellated cells were seen with reduced PFR2 staining at the distal tip of the new flagellum, without apparent modification of the old flagellum (Fig. 5E). This is explained by the fact that the PFR is assembled by addition of new subunits at the distal end of the new flagellum and that turn-over in the old flagellum is slow (Bastin et al., 1999a). In two separate experiments, we observed 53 or $57 \%$ of biflagellated cells where PFR2 abundance was clearly reduced in the new flagellum compared to the old one. After 15 hours, these cells failed completion of the late step of cytokinesis, with two progeny stuck to each other by their posterior end (Fig. 5F). Nevertheless, these cells were still able to duplicate their basal bodies and to assemble a new flagellum (PFR is not required for flagellum assembly), but the latter one did not stain with the anti-PFR2. These cells enter mitosis but again failed in cytokinesis and in contrast to procyclic stage trypanosomes appear to degenerate (Fig. 5F). This was confirmed by the reduced growth rate of cells transformed with PFR2 dsRNA compared to those electroporated with GFP dsRNA (data not shown). These results indicate that flagellum motility is also essential to complete cell separation in bloodstream form trypanosomes. 


\section{Discussion}

The attachment and arrangement of the trypanosome flagellum associated to the presence of the PFR whose integrity is required for correct cell motility (Bastin et al., 1998) represent unusual features that render investigation of movement challenging. Observation of live wild-type trypanosomes revealed the complex flagellum beating pattern, with a principal wave responsible for propulsion, propagating from tip to base. The flagellum frequently switched to a reverse wave that displayed high amplitude and low frequency. This allowed the cell to re-orient and hence to change direction. This alternating direction of wave propagation has been described in Crithidia (Holwill and McGregor, 1976) but not in Leishmania where only the tip-to-base wave is observed (Santrich et al., 1997).

RNAi targeting distinct representative of each axoneme structure (central pair, radial spokes, dynein arms) resulted in significant modifications of flagellum and cell motility, thus demonstrating that the axoneme is indeed functional in trypanosomes and that its constituents appear to behave in a related manner as to what was observed in Chlamydomonas and mammals. Analysis of Chlamydomonas inner and outer dynein arm mutants suggested different contributions in the control of beat frequency and waveform (Brokaw and Kamiya, 1987; Yagi et al., 2005). In T. brucei, absence of outer dynein arm in the (TbDNAI1)RNAi mutant is accompanied by absence of propulsive wave and loss of forward motility. Nevertheless, the reverse wave is still operating at an apparently normal beat frequency, indicating that inner dynein arms would be the main motor for this type of flagellar motility. Outer dynein arms are essential for reverse motility in Chlamydomonas, an organism that also swims with the flagella leading (Wilkinson et al., 1995; Pazour et al., 1999). Cooperation of various dynein motors has been reported previously in Chlamydomonas and is likely to also 
play an important role in the complex motility displayed by T. brucei. The presence of 9 axonemal dynein heavy chains indicates a sophistication equivalent to what had been observed in other organisms with complex beating pattern (Omoto et al., 1996; Porter, 1996). Silencing the T. brucei LC2 leads to a clear modification of swimming pattern that turned out to be jerky. This pattern is reminiscent to what had been observed in Chlamydomonas (Pazour et al., 1999), re-asserting the conserved function of the various dynein components in flagellum beating across species. Nevertheless, this did not prevent cells from moving forward and growth rate was not modified. The difference in behaviour compared to TbDNAII knockdown could possibly be linked to a slightly less efficient silencing of the $L C 2$ RNA as suggested by RT-PCR (Fig. S1).

The presence of a central pair of singlet microtubules with associated projections is a characteristic of motile flagella (Mitchell, 2004), albeit several types of motile cilia or flagella naturally devoid of central pair have been reported (Nonaka et al., 1998; Schrevel and Besse, 1975). Several proteins are specifically associated to the central pair and their inactivation usually drastically reduced flagellum motility in Chlamydomonas (Rupp et al., 2001; Smith and Lefebvre, 1996; Smith and Lefebvre, 1997; Yokoyama et al., 2004) and mice (Sapiro et al., 2002). In addition, patients with ultra-structural defects of the central pair displayed the most severe forms of primary ciliary dyskinesia (Tamalet et al., 2001). Our study revealed that the trypanosome central pair structure is asymmetric, with specific projections, is essential for flagellum motility and does not rotate relative to peripheral doublets. This latter characteristic is reminiscent to all metazoa examined to date but differs from what is encountered in Chlamydomonas (reviewed in (Omoto et al., 1999)). Our data revealed that the orientation seems slightly variable (Fig. 3D), a feature previously reported in Euglena gracilis, that like trypanosomes belong to the Euglenoid group and possess a PFR (Melkonian et al., 1982). The fixed orientation is preserved after detergent extraction, suggesting the 
existence of a specific system to maintain it. Although the orientation of the central pair relative to the axis of the PFR appears invariant, the positioning of the whole edifice (axoneme + PFR) on the cell body was more variable, probably as a consequence of motility. This indicates torsion of this dual complex, with some defined constraints as the PFR always appeared closer to the FAZ filament and the axoneme nearer to the adjacent smooth endoplasmic reticulum-associated microtubules. In contrast, flagellum arrangement along the cell body was frequently modified in axoneme mutants and numerous paralysed flagella are partially or sometimes completely detached from the cell body (with the exception of anchoring via the basal body-flagellar pocket), suggesting that this physical constraint is modified.

Intriguingly, the orientation of the central pair is highly variable in (TbPF16)RNAi, (TbPF20)RNAi and (TbDNAI1)RNAi mutants. In Chlamydomonas, the central pair twists during flagellum bending as to adopt a specific orientation with the $\mathrm{C} 1$ microtubule towards the active dynein doublet (Mitchell, 2003a; Wargo and Smith, 2003). However, in vitro reactivation of isolated axonemes showed that this orientation is lost in radial spoke and outer dynein arm mutants (the latter case only in the presence of high calcium concentration). These results suggest interactions between the central pair complex and the outer dynein arms and are consistent between trypanosomes and green algae, despite the different behaviour of the central pair. The loss of specific outer dynein arms in both central pair mutants in trypanosomes also underlines the likelihood of such interactions. Comparison of axonemes from T. brucei and from Chlamydomonas revealed several differences, including in central pair projections and radial spoke heads. Identifying the differences between flagella of organisms with a rotating or a fixed central pair will be challenging. In any case, these data underline once more the complexity of the central pair apparatus (Mitchell, 2004) and highlight the need for detailed examination of cilia and flagella from different origins. 
Overall, our results demonstrate that the trypanosome axoneme possesses typical ultrastructural and molecular features of conventional 9+2 axonemes and that the central pair maintains a fixed orientation. Combined to the availability of the complete genome sequence and the amenability of reverse genetics, this makes the trypanosome an attractive model to study genes involved in human genetic diseases linked to flagellum motility defects. Central pair defects are amongst the most severe cases of primary ciliary dyskinesia (Tamalet et al., 2001) and modifications of central pair orientation have been reported (Rutland and de Iongh, 1990). In addition, DNAI1 was the first gene whose importance in human genetic diseases has been revealed (Pennarun et al., 1999) and the similarity between ultra-structural defects seen in patients and the RNAi phenotype reported here opens the opportunity for functional studies of human genes in trypanosomes. Functional complementation of RNAi mutants by expression of heterologous genes from $T$. cruzi has been successful without cross-RNAi (Rusconi et al., 2005), suggesting it could be attempted for human genes.

These resulted prompted us to re-examine the comportment of PFR mutants that present a normal axoneme at the ultra-structural level but that are not able to swim (Bastin et al., 1998). Our data show that the distal tip is still motile in many flagella, displaying an almost normal wave amplitude, but that the waves are not propagating towards the base properly. The flagellum alternates rapidly between main (direct) and reverse wave without effective motility. This could be linked to the striking change in shape as these trypanosomes do not exhibit the usual twisted aspect with the flagellum around the cell body. Instead, PFR mutant cells appeared bent at right angle with an almost straight posterior end. These data support the hypothesis that the PFR participates to cell motility in contributing to flagellum strengthening during wave propagation (Santrich et al., 1997). In the related parasite Leishmania, the flagellum is only tethered along a short region of the cell body where it exits from the flagellar pocket. FAZ filament and four microtubules are present at this site (Wiese 
et al., 2003) and immunofluorescence with trypanosome anti-FAZ antibodies stains that area distinctly (unpublished data). Dark field microscopy with stroboscopic illumination showed that wave propagation is also reduced in proximity to the cell body, suggesting a related function in Leishmania (Santrich et al., 1997). PFR2 knock-out mutants of Leishmania retained the ability to produce waves but with lower amplitude and these were drastically reduced as the wave progressed in direction of the cell body. Finally, flagella movements also appeared planar in PFR2 knock-out cells (Santrich et al., 1997), suggesting that the PFR could contribute to the complex three dimensional swimming pattern of trypanosomes and

\section{Leishmania.}

In trypanosomes as in many groups of protists, the new flagellum is constructed whilst the old one remains present (Brugerolle, 1992; Noel et al., 2003; Sherwin and Gull, 1989). Both flagella are beating throughout this process and during the progression of cytokinesis, the daughter cells re-orientate in such a way that their flagella are pointing towards opposite directions. As a result, movement of these two flagella, added to the twisted motility imposed by the flagellum disposition around the cell body (Hill, 2003), exerts tension on the midbody and contributes to completion of cell separation. Other modes of movement participate to this process in the ciliate Tetrahymena and in the slime mould Dictyostelium, where the shearing force is provided by complex cilia beating (Brown et al., 1999) and amoeboid movement (Tuxworth et al., 1997) respectively. In all three cases, cells could re-enter the normal cell cycle, progress through mitosis and therefore end up multi-nucleated, indicating the absence of a checkpoint on that final stage of cell division. Separation defects were rare in PFR mutants, an observation that might be related to the fact that these cells are still able to move and exhibit twisting movements that could be sufficient to allow cytokinesis. Similarly, no striking cytokinesis defects were noted in (TbDNAI1)RNAi mutants or trypanin mutants (Hutchings et al., 2002) that both can beat but without net forward motility. 


\section{Acknowledgements}

We wish to thank Kent Hill for sharing data prior to publication and thorough critical reading of the manuscript, Mark Field for providing access to his laboratory for endocytosis experiments, Martin Wiese for providing unpublished data on Leishmania flagellum and helpful comments, David Mitchell for stimulating discussions, Derrick Robinson and Mélanie Bonhivers for critical reading of the manuscript, Keith Gull, George Cross and Paul Englund for providing monoclonal antibodies, inducible trypanosome cell line and plasmids respectively, and Sabrina Absalon and Estelle Escudier for helpful comments. We also acknowledge the electron microscopy department of the Muséum National d'Histoire Naturelle for providing access to their equipment. Sequencing of Trypanosoma brucei genome was accomplished at TIGR and the Sanger Institute with support from NIAID and the Wellcome Trust, respectively. This work was funded by an ACI grant "Dynamique et Réactivité des Assemblages Biologiques”, by an ACI grant in Development Biology and by a GIS grant on rare genetic diseases. C.B. was funded by a European Science Foundation fellowship and L.K.'s trip in London was funded by a short-term EMBO fellowship. 


\section{References}

Bastin, P., Ellis, K., Kohl, L. and Gull, K. (2000). Flagellum ontogeny in trypanosomes studied via an inherited and regulated RNA interference system. J Cell Sci 113, 3321-8.

Bastin, P., MacRae, T. H., Francis, S. B., Matthews, K. R. and Gull, K. (1999a). Flagellar morphogenesis: protein targeting and assembly in the paraflagellar rod of trypanosomes. Mol Cell Biol 19, 8191-200.

Bastin, P., Matthews, K. R. and Gull, K. (1996). The paraflagellar rod of kinetoplastida: solved and unsolved questions. Parasitol Today 12, 302-7.

Bastin, P., Pullen, T. J., Sherwin, T. and Gull, K. (1999b). Protein transport and flagellum assembly dynamics revealed by analysis of the paralysed trypanosome mutant snl1. J Cell Sci 112, 3769-77.

Bastin, P., Sherwin, T. and Gull, K. (1998). Paraflagellar rod is vital for trypanosome motility. Nature 391, 548.

Beisson, J. and Wright, M. (2003). Basal body/centriole assembly and continuity. Curr Opin Cell Biol 15, 96-104.

Berriman, M. Ghedin, E. Hertz-Fowler, C. Blandin, G. Renauld, H. Bartholomeu, D. C. Lennard, N. J. Caler, E. Hamlin, N. E. Haas, B. et al. (2005). The genome of the African trypanosome Trypanosoma brucei. Science 309, 416-22.

Briggs, L. J., Davidge, J. A., Wickstead, B., Ginger, M. L. and Gull, K. (2004). More than one way to build a flagellum: comparative genomics of parasitic protozoa. Curr Biol 14, R611-2.

Brokaw. (1972). Flagellar movement: a sliding filament model. Science 178, 455-62. 
Brokaw, C. J. and Kamiya, R. (1987). Bending patterns of Chlamydomonas flagella: IV. Mutants with defects in inner and outer dynein arms indicate differences in dynein arm function. Cell Motil Cytoskeleton 8, 68-75.

Brown, J. M., Hardin, C. and Gaertig, J. (1999). Rotokinesis, a novel phenomenon of cell locomotion-assisted cytokinesis in the ciliate Tetrahymena thermophila. Cell Biol Int 23, 841-8.

Brugerolle, G. (1992). Flagellar apparatus duplication and partition, flagellar transformation during division in Entosiphon sulcatum. Biosystems 28, 203-9.

Deflorin, J., Rudolf, M. and Seebeck, T. (1994). The major components of the paraflagellar rod of Trypanosoma brucei are two similar, but distinct proteins which are encoded by two different gene loci. J Biol Chem 269, 28745-28751.

DiBella, L. M. and King, S. M. (2001). Dynein motors of the Chlamydomonas flagellum. Int Rev Cytol 210, 227-68.

Durand-Dubief, M. and Bastin, P. (2003). TbAGO1, an Argonaute protein required for RNA interference, is involved in mitosis and chromosome segregation in Trypanosoma brucei. BMC Biol 1, 2.

Durand-Dubief, M., Kohl, L. and Bastin, P. (2003). Efficiency and specificity of RNA interference generated by intra- and intermolecular double stranded RNA in Trypanosoma brucei. Mol Biochem Parasitol 129, 11-21.

Eley, L., Yates, L. M. and Goodship, J. A. (2005). Cilia and disease. Current Opinion in Genetics \& Development 15, 308-314.

Gull, K. (2003). Host-parasite interactions and trypanosome morphogenesis: a flagellar pocketful of goodies. Curr Opin Microbiol 6, 365-70.

Hemphill, A., Lawson, D. and Seebeck, T. (1991). The cytoskeletal architecture of Trypanosoma brucei. J Parasitol 77, 603-12. 
Hill, K. L. (2003). Biology and mechanism of trypanosome cell motility. Eukaryot Cell 2, 200-8.

Hirumi, H. and Hirumi, K. (1989). Continuous cultivation of Trypanosoma brucei blood stream forms in a medium containing a low concentration of serum protein without feeder cell layers. J Parasitol. 75, 985-989.

Holwill, M. E. and McGregor, J. L. (1976). Effects of calcium on flagellar movement in the trypanosome Crithidia oncopelti. J Exp Biol 65, 229-42.

Hutchings, N. R., Donelson, J. E. and Hill, K. L. (2002). Trypanin is a cytoskeletal linker protein and is required for cell motility in African trypanosomes. $J$ Cell Biol 156, 86777.

Kamiya, R. (2002). Functional diversity of axonemal dyneins as studied in Chlamydomonas mutants. Int Rev Cytol 219, 115-55.

Kohl, L. and Bastin, P. (2005). The Flagellum of trypanosomes. Int Rev Cytol 244, 227-285.

Kohl, L., Robinson, D. and Bastin, P. (2003). Novel roles for the flagellum in cell morphogenesis and cytokinesis of trypanosomes. Embo J 22, 5336-46.

Kohl, L., Sherwin, T. and Gull, K. (1999). Assembly of the paraflagellar rod and the flagellum attachment zone complex during the Trypanosoma brucei cell cycle. J Eukaryot Microbiol 46, 105-9.

Maga, J. A. and LeBowitz, J. H. (1999). Unravelling the kinetoplastid paraflagellar rod. Trends Cell Biol 9, 409-13.

Maga, J. A., Sherwin, T., Francis, S., Gull, K. and LeBowitz, J. H. (1999). Genetic dissection of the Leishmania paraflagellar rod, a unique flagellar cytoskeleton structure. $J$ Cell Sci 112, 2753-63.

McKean, P. G., Baines, A., Vaughan, S. and Gull, K. (2003). Gamma-tubulin 
functions in the nucleation of a discrete subset of microtubules in the eukaryotic flagellum. Curr Biol 13, 598-602.

Melkonian, M., Robenek, H. and Rassat, J. (1982). Flagellar membrane specializations and their relationship to mastigonemes and microtubules in Euglena gracilis. $J$ Cell Sci 55, 115-35.

Mitchell, D. R. (2003a). Orientation of the central pair complex during flagellar bend formation in Chlamydomonas. Cell Motil Cytoskeleton 56, 120-9.

Mitchell, D. R. (2003b). Reconstruction of the projection periodicity and surface architecture of the flagellar central pair complex. Cell Motil Cytoskeleton 55, 188-99.

Mitchell, D. R. (2004). Speculations on the evolution of 9+2 organelles and the role of central pair microtubules. Biol Cell 96, 691-6.

Ngô, H., Tschudi, C., Gull, K. and Ullu, E. (1998). Double-stranded RNA induces mRNA degradation in Trypanosoma brucei. Proc Natl Acad Sci U S A 95, 14687-92.

Noel, C., Gerbod, D., Delgado-Viscogliosi, P., Fast, N. M., Younes, A. B., Chose, O., Roseto, A., Capron, M. and Viscogliosi, E. (2003). Morphogenesis during division and griseofulvin-induced changes of the microtubular cytoskeleton in the parasitic protist, Trichomonas vaginalis. Parasitol Res 89, 487-94.

Nonaka, S., Tanaka, Y., Okada, Y., Takeda, S., Harada, A., Kanai, Y., Kido, M. and Hirokawa, N. (1998). Randomization of left-right asymmetry due to loss of nodal cilia generating leftward flow of extraembryonic fluid in mice lacking KIF3B motor protein. Cell 95, 829-37.

Omoto, C. K., Gibbons, I. R., Kamiya, R., Shingyoji, C., Takahashi, K. and Witman, G. B. (1999). Rotation of the central pair microtubules in eukaryotic flagella. $\mathrm{Mol}$ Biol Cell 10, 1-4.

Omoto, C. K. and Kung, C. (1979). The pair of central tubules rotates during ciliary 
beat in Paramecium. Nature 279, 532-4.

Omoto, C. K., Yagi, T., Kurimoto, E. and Kamiya, R. (1996). Ability of paralyzed flagella mutants of Chlamydomonas to move. Cell Motil Cytoskeleton 33, 88-94.

Pan, J., Wang, Q. and Snell, W. J. (2005). Cilium-generated signaling and ciliarelated disorders. Lab Invest $\mathbf{8 5}, 452-63$.

Pazour, G. J., Koutoulis, A., Benashski, S. E., Dickert, B. L., Sheng, H., PatelKing, R. S., King, S. M. and Witman, G. B. (1999). LC2, the Chlamydomonas homologue of the $t$ complex-encoded protein Tctex2, is essential for outer dynein arm assembly. Mol Biol Cell 10, 3507-20.

Pennarun, G., Escudier, E., Chapelin, C., Bridoux, A. M., Cacheux, V., Roger, G., Clement, A., Goossens, M., Amselem, S. and Duriez, B. (1999). Loss-of-function mutations in a human gene related to Chlamydomonas reinhardtii dynein IC78 result in primary ciliary dyskinesia. Am J Hum Genet 65, 1508-19.

Piperno, G., Mead, K. and Shestak, W. (1992). The inner dynein arms I2 interact with a "dynein regulatory complex" in Chlamydomonas flagella. J Cell Biol 118, 1455-63.

Porter, M. E. (1996). Axonemal dyneins: assembly, organization, and regulation. Curr Opin Cell Biol 8, 10-7.

Rupp, G., O'Toole, E. and Porter, M. E. (2001). The Chlamydomonas PF6 locus encodes a large alanine/proline-rich polypeptide that is required for assembly of a central pair projection and regulates flagellar motility. Mol Biol Cell 12, 739-51.

Rupp, G. and Porter, M. E. (2003). A subunit of the dynein regulatory complex in Chlamydomonas is a homologue of a growth arrest-specific gene product. J Cell Biol 162, 4757.

Rusconi, F., Durand-Dubief, M. and Bastin, P. (2005). Functional complementation of RNA interference mutants in trypanosomes. BMC Biotechnol 5, 6 . 
Russell, D. G., Newsam, R. J., Palmer, G. C. and Gull, K. (1983). Structural and biochemical characterisation of the paraflagellar rod of Crithidia fasciculata. Eur J Cell Biol 30, $137-43$.

Rutland, J. and de Iongh, R. U. (1990). Random ciliary orientation. A cause of respiratory tract disease. $N$ Engl $J$ Med 323, 1681-4.

Sale, W. S. (1986). The axonemal axis and Ca2+-induced asymmetry of active microtubule sliding in sea urchin sperm tails. J Cell Biol 102, 2042-52.

Santrich, C., Moore, L., Sherwin, T., Bastin, P., Brokaw, C., Gull, K. and LeBowitz, J. H. (1997). A motility function for the paraflagellar rod of Leishmania parasites revealed by PFR-2 gene knockouts. Mol Biochem Parasitol 90, 95-109.

Sapiro, R., Kostetskii, I., Olds-Clarke, P., Gerton, G. L., Radice, G. L. and Strauss, I. J. (2002). Male infertility, impaired sperm motility, and hydrocephalus in mice deficient in sperm-associated antigen 6. Mol Cell Biol 22, 6298-305.

Sapiro, R., Tarantino, L. M., Velazquez, F., Kiriakidou, M., Hecht, N. B., Bucan, M. and Strauss, J. F., 3rd. (2000). Sperm antigen 6 is the murine homologue of the Chlamydomonas reinhardtii central apparatus protein encoded by the PF16 locus. Biol Reprod 62, 511-8.

Schlaeppi, K., Deflorin, J. and Seebeck, T. (1989). The major component of the paraflagellar rod of Trypanosoma brucei is a helical protein that is encoded by two identical, tandemly linked genes. J Cell Biol 109, 1695-709.

Schrevel, J. and Besse, C. (1975). [A functional flagella with a $6+0$ pattern]. J Cell Biol 66, 492-507.

Sherwin, T. and Gull, K. (1989). The cell division cycle of Trypanosoma brucei brucei: timing of event markers and cytoskeletal modulations. Philos Trans R Soc Lond B Biol Sci 323, 573-88. 
Sherwin, T., Schneider, A., Sasse, R., Seebeck, T. and Gull, K. (1987). Distinct localization and cell cycle dependence of $\mathrm{COOH}$ terminally tyrosinolated alpha-tubulin in the microtubules of Trypanosoma brucei brucei. J Cell Biol 104, 439-46.

Silflow, C. D. and Lefebvre, P. A. (2001). Assembly and Motility of Eukaryotic Cilia and Flagella. Lessons from Chlamydomonas reinhardtii. Plant Physiol. 127, 1500-1507.

Smith, E. F. and Lefebvre, P. A. (1996). PF16 encodes a protein with armadillo repeats and localizes to a single microtubule of the central apparatus in Chlamydomonas flagella. J Cell Biol 132, 359-70.

Smith, E. F. and Lefebvre, P. A. (1997). PF20 gene product contains WD repeats and localizes to the intermicrotubule bridges in Chlamydomonas flagella. Mol Biol Cell 8, 455-67.

Smith, E. F. and Sale, W. S. (1992). Regulation of dynein-driven microtubule sliding by the radial spokes in flagella. Science 257, 1557-9.

Tamalet, A., Clement, A., Roudot-Thoraval, F., Desmarquest, P., Roger, G., Boule, M., Millepied, M. C., Baculard, T. A. and Escudier, E. (2001). Abnormal central complex is a marker of severity in the presence of partial ciliary defect. Pediatrics 108, E86.

Tamm, S. L. and Tamm, S. (1981). Ciliary reversal without rotation of axonemal structures in ctenophore comb plates. J Cell Biol 89, 495-509.

Tuxworth, R. I., Cheetham, J. L., Machesky, L. M., Spiegelmann, G. B., Weeks, G. and Insall, R. H. (1997). Dictyostelium RasG is required for normal motility and cytokinesis, but not growth. J Cell Biol 138, 605-14.

Vickerman, K. (1962). The mechanism of cyclical development in trypanosomes of the Trypanosoma brucei sub-group: an hypothesis based on ultrastructural observations. Trans R Soc Trop Med Hyg 56, 487-95.

Vickerman, K. (1976). Comparative cell biology of the kinetoplastid flagellates. WHR Lumsden, DA Evans (eds), Biology of the Kinetoplastida, Academic Press, London/New 
York/San Francisco, 35-130.

Wang, Z., Morris, J. C., Drew, M. E. and Englund, P. T. (2000). Inhibition of Trypanosoma brucei gene expression by RNA interference using an integratable vector with opposing T7 promoters. J Biol Chem 275, 40174-9.

Wargo, M. J. and Smith, E. F. (2003). Asymmetry of the central apparatus defines the location of active microtubule sliding in Chlamydomonas flagella. Proc Natl Acad Sci US A 100, 137-42.

Wiese, M., Kuhn, D. and Grunfelder, C. G. (2003). Protein kinase involved in flagellar-length control. Eukaryot Cell 2, 769-77.

Wilkerson, C. G., King, S. M., Koutoulis, A., Pazour, G. J. and Witman, G. B. (1995). The 78,000 M(r) intermediate chain of Chlamydomonas outer arm dynein isa WDrepeat protein required for arm assembly. $J$ Cell Biol 129, 169-78.

Williams, B. D., Velleca, M. A., Curry, A. M. and Rosenbaum, J. L. (1989). Molecular cloning and sequence analysis of the Chlamydomonas gene coding for radial spoke protein 3: flagellar mutation pf-14 is an ochre allele. $J$ Cell Biol 109, 235-45.

Wirtz, E., Leal, S., Ochatt, C. and Cross, G. A. (1999). A tightly regulated inducible expression system for conditional gene knock-outs and dominant-negative genetics in Trypanosoma brucei. Mol Biochem Parasitol 99, 89-101.

Witman, G. B., Plummer, J. and Sander, G. (1978). Chlamydomonas flagellar mutants lacking radial spokes and central tubules. Structure, composition, and function of specific axonemal components. J Cell Biol 76, 729-47.

Woods, A., Sherwin, T., Sasse, R., MacRae, T. H., Baines, A. J. and Gull, K. (1989). Definition of individual components within the cytoskeleton of Trypanosoma brucei by a library of monoclonal antibodies. $J$ Cell Sci $\mathbf{9 3}, 491-500$.

\section{Yagi, T., Minoura, I., Fujiwara, A., Saito, R., Yasunaga, T., Hirono, M. and}


Kamiya, R. (2005). An axonemal dynein particularly important for flagellar movement at high viscosity. Implications from a new Chlamydomonas mutant deficient in the dynein heavy chain gene DHC9. J Biol Chem 280, 41412-20.

Yokoyama, R., O'toole, E., Ghosh, S. and Mitchell, D. R. (2004). Regulation of flagellar dynein activity by a central pair kinesin. Proc Natl Acad Sci U S A $\mathbf{5 0 .}$

Zhang, Z., Sapiro, R., Kapfhamer, D., Bucan, M., Bray, J., Chennathukuzhi, V., McNamara, P., Curtis, A., Zhang, M., Blanchette-Mackie, E. J. et al. (2002). A spermassociated WD repeat protein orthologous to Chlamydomonas PF20 associates with Spag6, the mammalian orthologue of Chlamydomonas PF16. Mol Cell Biol 22, 7993-8004. 


\section{Figure legends}

Fig. 1. Structural and molecular aspects of the trypanosome flagellum.

A. Cartoon of cross-section through the T. brucei flagellum, indicating predicted location of proteins studied in this work. Microtubules are shown in black, nexin links in green, radial spokes in magenta, dynein arms in orange and central pair projections in green. The PFR is shown in blue, with its proximal, intermediate and distal domain (relative to the axoneme). The inset shows a magnified central pair and its projections. To measure orientation of the central pair relative to the PFR, lines were drawn on the axis passing through the two microtubules or through the proximal domain of the PFR (dashed) and angles measured. B. Cross-sections of wild type flagellum from whole cells. Left image: the flagellum appears to lie on its side, with the PFR in proximity of the FAZ filament (dark spot between subpellicular microtubules) and the axoneme closer to the four specialised microtubules associated to the smooth endoplasmic reticulum (left side of the image). Right image, the PFR is positioned between the cell body and the axoneme. C. Cross-section of demembranated flagellum where dynein arms, radial spokes and central pair projections are more visible. D. Longitudinal section of the flagellum showing the axoneme (Axo) with the central pair (CP) microtubules and some projections and the paraflagellar rod (PFR) confined between the axoneme and the cell body. E. Representation of proteins analysed in this study with their main particular domains (from Pfam domain searches). F. Percentage of identity between flagellum proteins from T. brucei and two other Kinetoplastid, T. cruzi and L. major and between human, mouse and Chlamydomonas reinhardtii. Alignment was performed using the Jotun Hein method, except for TbDNAH where Clustal W was used. 
Fig. 2. Sedimentation shows reduction of motility. Trypanosomes were incubated in cuvettes and optical density was measured before and after mixing. The recipient cell line 29-13 and an induced sample of the F6 RNAi mutant (hypothetical protein not involved in motility) were used as a negative controls and the PFR2 RNAi mutant snl-2 as positive control. RNAi mutant cell lines were induced for two days and grown with (full lines) or without (dotted lines) shaking. Reduction in cell motility was severe in both conditions.

Fig. 3. Central pair presence and orientation in normal and mutant cell lines. A. Cross-sections of flagella from (TbPF16)RNAi and (TbPF20)RNAi cells induced for 3 days. The central pair can be positioned at very different angles relative to the PFR axis. In several sections, one or both microtubule of the central pair can be absent. B. Loss of one or more their outer dynein arms in (TbPF20)RNAi and (TbPF16)RNAi mutants and of all of them in (TbDNAI1) RNAi mutants. Yellow arrows indicate the position of the missing arm. C. Longitudinal section of a (TbPF16)RNAi mutant where the central pair is visible in a bent region, in this case it appears parallel to the bend plane. D. Central pair orientation relative to the PFR proximal axis. A negative angle indicates that lines drawn from the axis of the central pair and of the PFR would cross in direction of doublet 4 of the axoneme (the right side on these images). Sections were classified as belonging to any 15 degree interval. Due to the difficulty in unambiguously distinguishing the $\mathrm{C} 1$ from the $\mathrm{C} 2$ microtubule, angles were limited to 180 degrees but could be more important. As no significant differences could be seen between sections of whole cells or demembranated samples, data from both sets were pooled. From top to bottom: wild-type (n=82), (TbPF20)RNAi ( $n=65),($ TbPF16)RNAi $(\mathrm{n}=116)$ and (TbDNAI1)RNAi $(\mathrm{n}=44)$. Whereas a determined orientation is found in wildtype cells, it appeared highly variable in axoneme mutants. 
Fig. 4. Cumulative growth curves of the axoneme or PFR mutants in non induced conditions (full line), induced conditions (dashed line) and induced in shaking conditions (dotted line).

Fig. 5. Cell body separation is impaired when axoneme mobility is strongly affected. Panel AC represent still images of movies of (TbPF16)RNAi mutants non-induced (A) or induced for 48 (B) or 72 (C) hours. A. Both flagella are motile and the cell is actively moving and twisting, but no net movement is observed. B. The left flagellum is motile but not the right one. The active flagellum drags the couple towards its anterior end. C. Both flagella are paralysed and division is slowed down. D. Field of (TbPF20)RNAi mutant cells induced for 72 hours, grown in unshaken conditions (left) or shaken conditions. Large cell aggregates are visible in unshaken conditions, most of them disappearing upon shaking. E: Bloodstream form trypanosomes electroporated with GFP (left) or PFR2 (right) dsRNA. After 5 hours, flagella were labelled with the anti-PFR2 antibody (green, bottom) and DNA stained with DAPI (blue) and superimposed to the phase contrast image (top). Cells with two flagella that received GFP dsRNA showed complete PFR2 staining in both flagella whereas those with PFR2 dsRNA exhibited absence of PFR2 at the distal part of the flagellum, which is the normal site of PFR construction. F. After 18 hours, couple of cells having failed in separation (left images) were abundant only in the PFR2-transfected samples. These could re-enter the cell cycle (center images) but rapidly degenerated (right images). 
Table 1: Presence of central pair microtubules

\begin{tabular}{lccc}
\hline Cell type & \multicolumn{4}{c}{ Number of microtubules in the central pair $(\%)$} \\
\cline { 1 - 3 } WT $(\mathrm{n}=40)$ & 2 & 1 & 0 \\
\hline (TbPF16)RNAi $(\mathrm{n}=83)$ & 97.5 & 2.5 & 0 \\
\hline (TbPF20)RNAi $(\mathrm{n}=69)$ & 78.3 & 18 & 3.7 \\
\hline (TbDNAI1)RNAi $(\mathrm{n}=23)$ & 100 & 20.2 & 0 \\
\hline
\end{tabular}


Table 2 : Outer dynein presence in various cell lines

\begin{tabular}{lccccc}
\hline Cell type & Total images* & \multicolumn{3}{c}{ Outer dynein arms } \\
\cline { 1 - 2 } All present & 1-3 missing & >3 missing \\
\hline WT-whole cells & 40 & 40 & 0 & 0 \\
\hline WT-detergent-treated & 30 & 30 & 0 & 0 \\
\hline (TbPF16)RNAi w.c. & 34 & 8 & 25 & 1 \\
\hline (TbPF16)RNAi d.t. & 20 & 11 & 9 & 0 \\
\hline (TbPF20)RNAi w.c. & 11 & 7 & 4 & 0 \\
\hline (TbPF20)RNAi d.t. & 32 & 16 & 16 & 0 \\
\hline (TbDNAI1) RNAi d.t. & 43 & 1 & 5 & 37 \\
\hline
\end{tabular}

*Only images where outer dynein arms could unambiguously be recognised were selected for analysis, hence the reduced number of samples 
A.

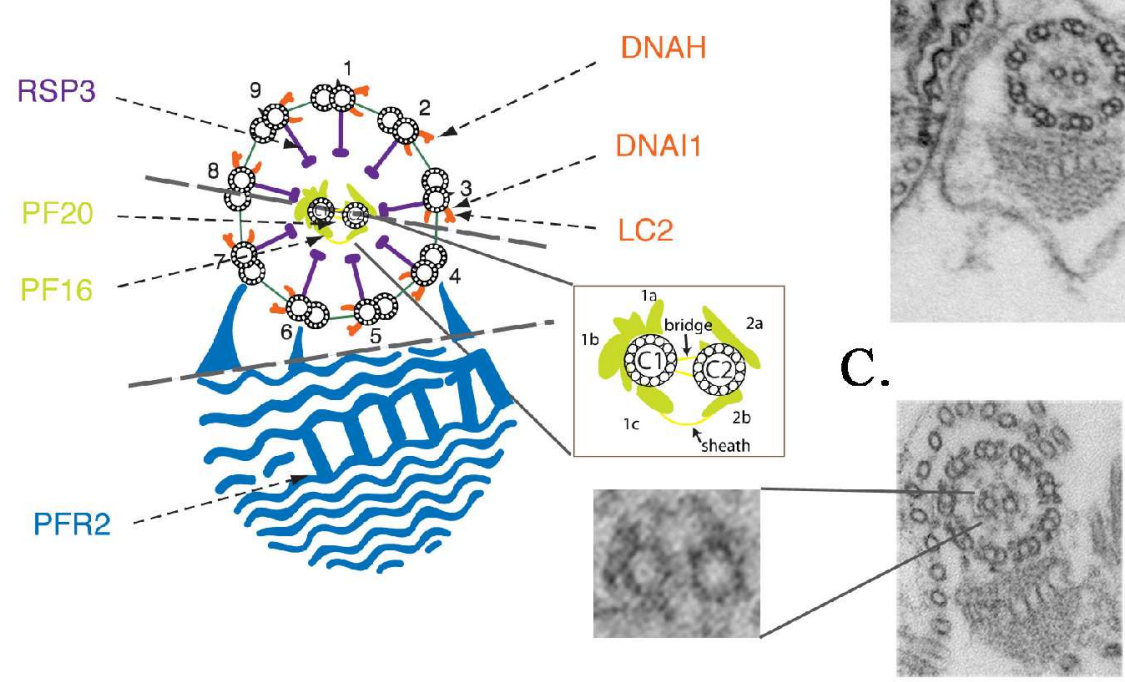

E.

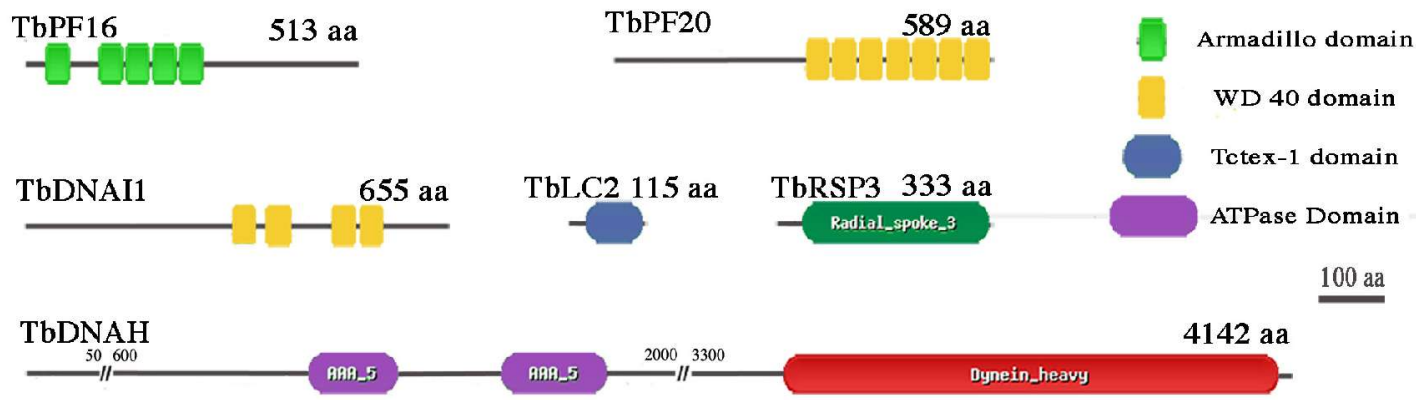

F.

\begin{tabular}{lc|cc|c|c|c|c} 
Species & TbPF16 & TbPF20 & TbDNAI1 & TbDNAH & TbRSP3 & TbLC2 & TbPFR2 \\
\hline T.cruzi & 91.2 & 70.8 & 78.5 & 74.4 & 84.1 & 76.2 & 93.2 \\
L.major & 82.4 & 49.7 & 61.5 & 59.4 & 62.7 & 62.7 & 82.1 \\
H.sapiens & 63.1 & 30.4 & 40.4 & 28.4 & 27.8 & 23.8 & - \\
M.musculus & 64.6 & 31.5 & 40.8 & 28.5 & 29.4 & 29.5 & - \\
C.reinhardtii & 56.4 & 36.7 & 40.6 & 28.2 & 43.8 & 33.6 & - \\
\hline
\end{tabular}

Fig.1

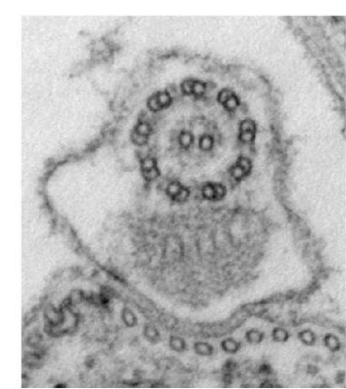

D.

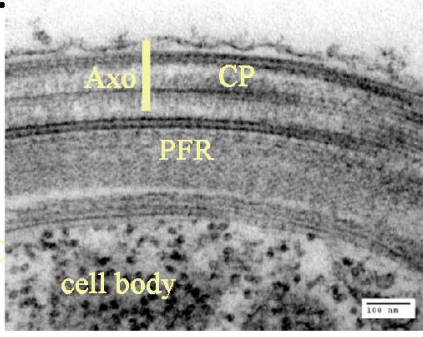




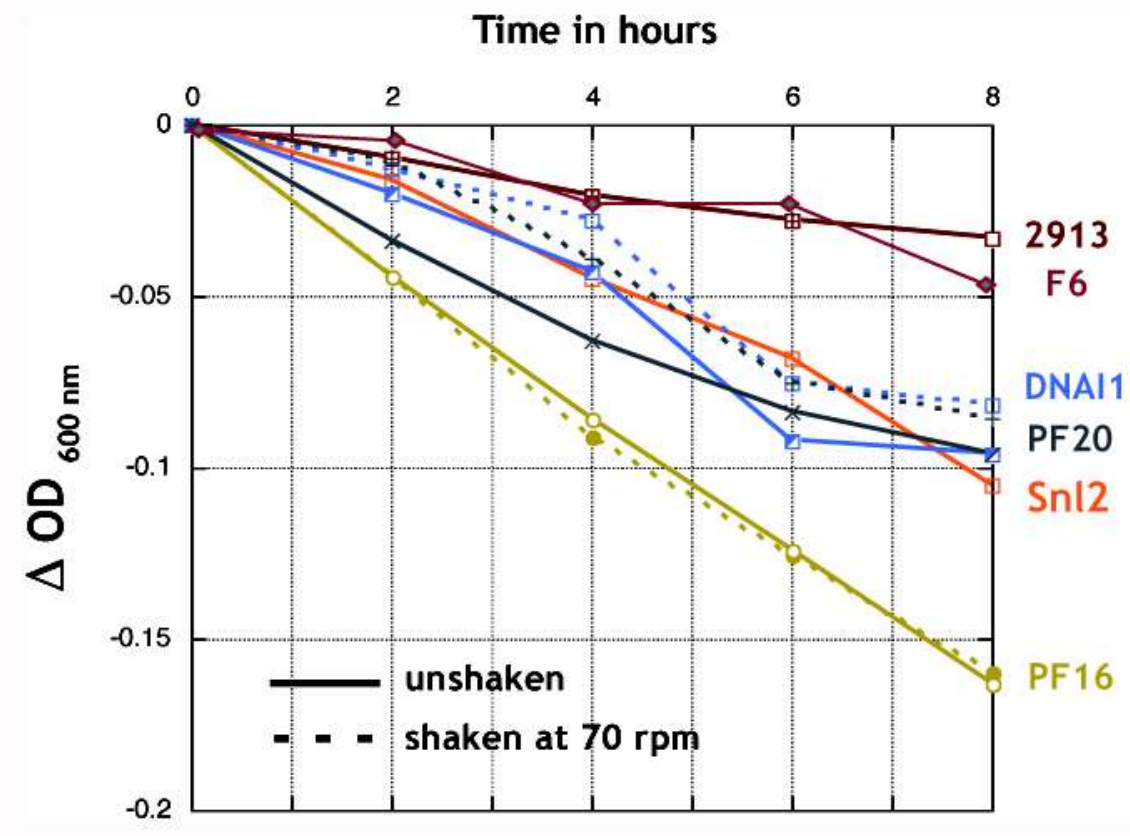

Fig.2 
Figure 3:
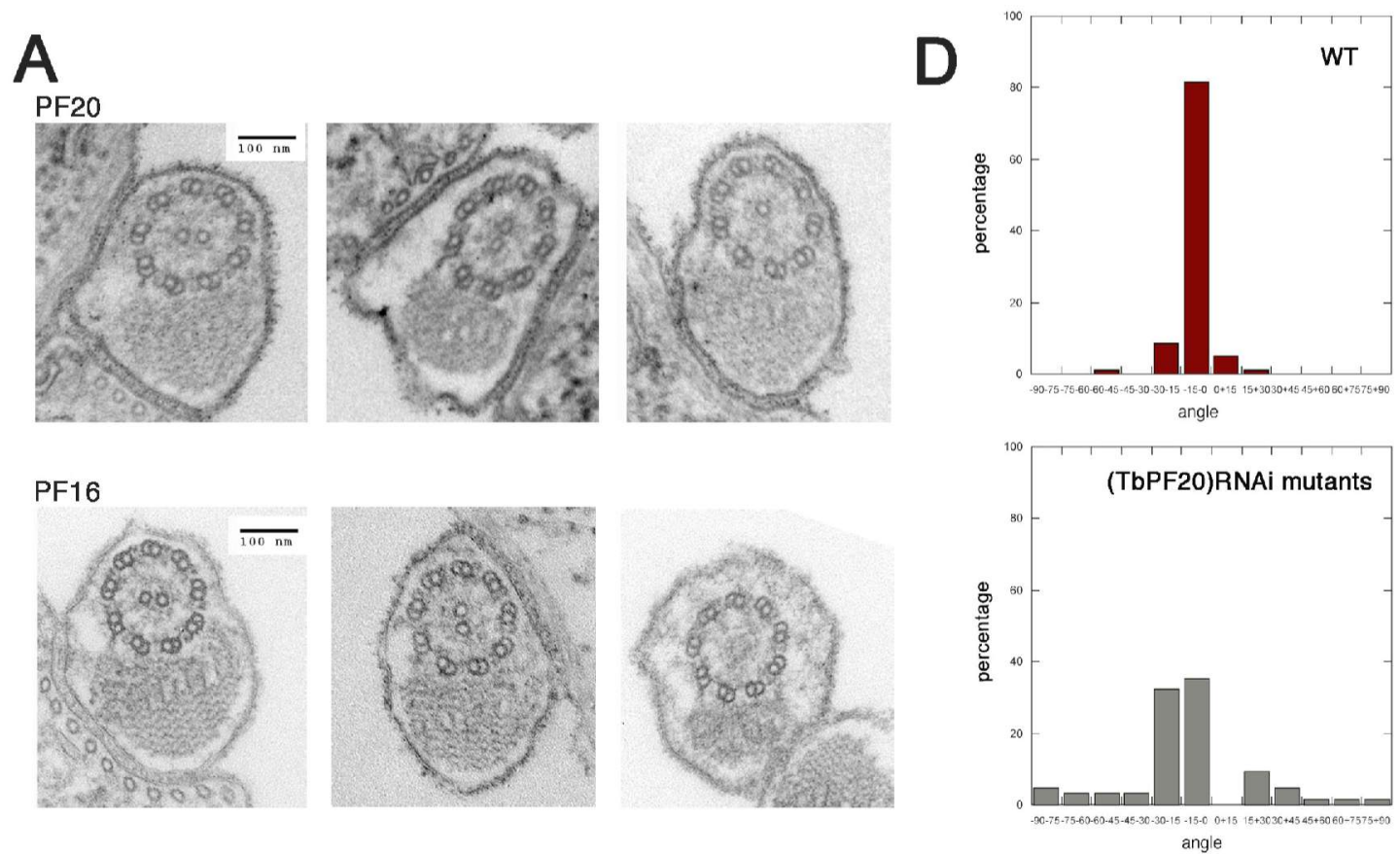

B
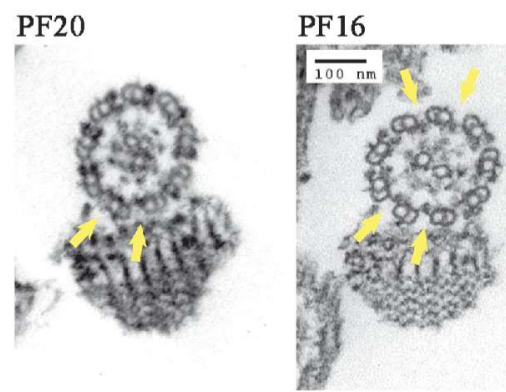

DNAI1
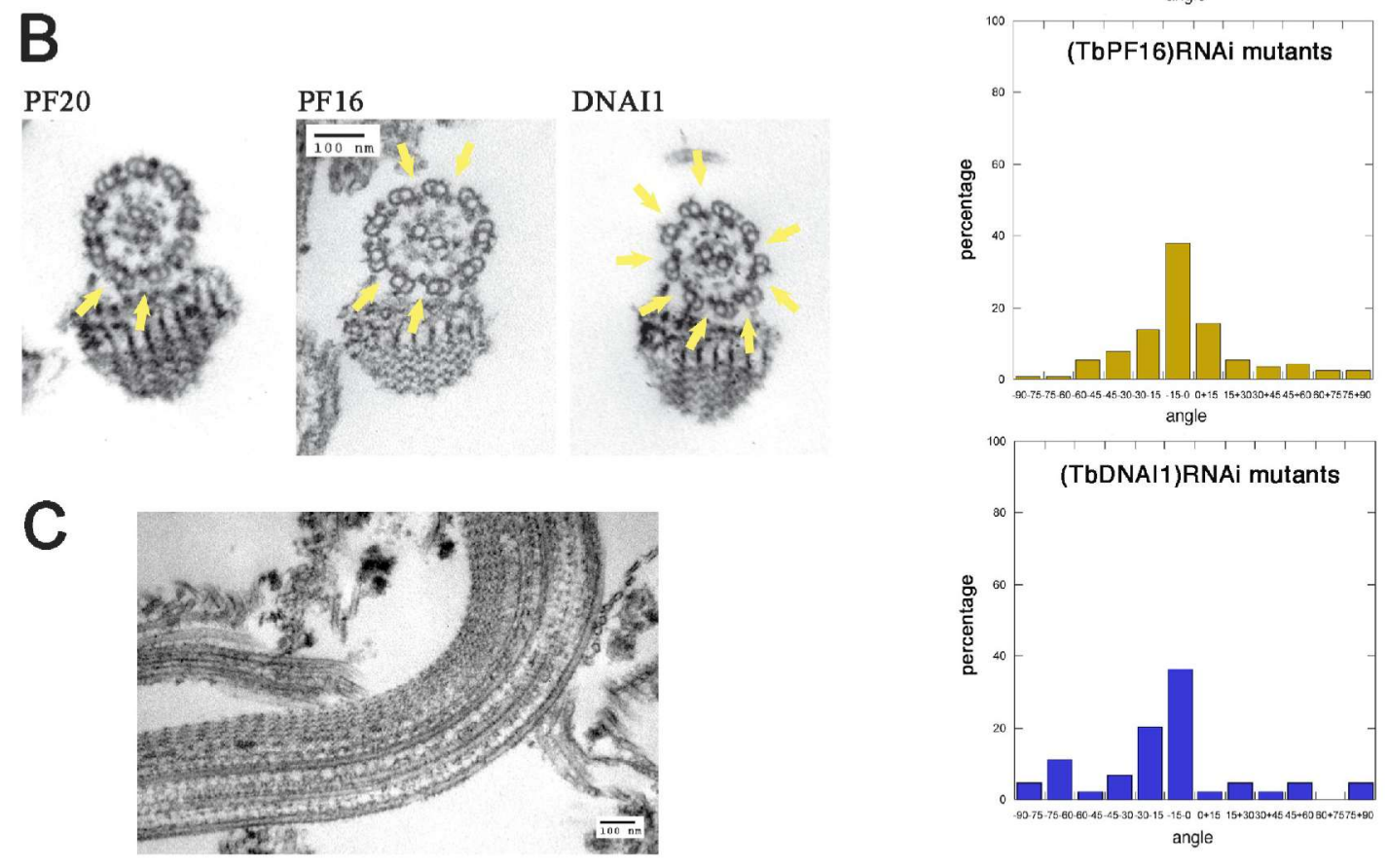

Fig.3 
(TbPF16)RNAi mutants

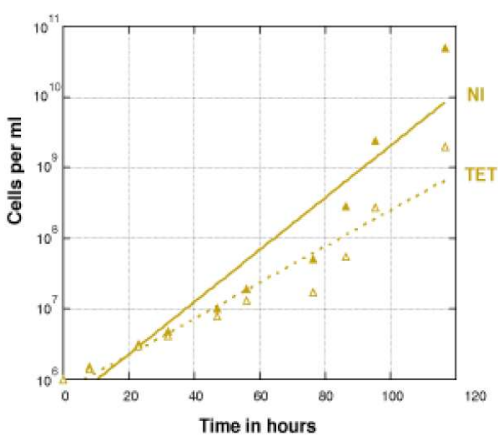

(TbDNAH)RNAi mutants

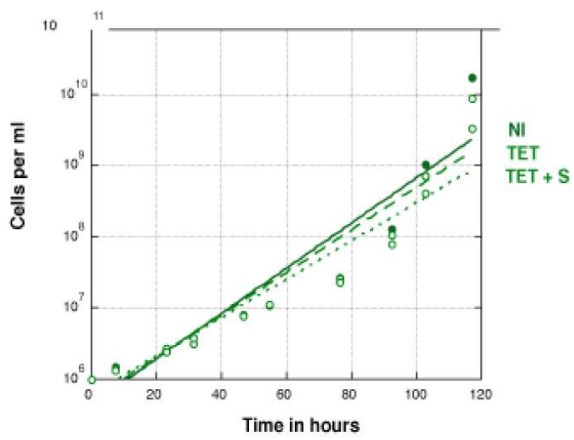

(TbPF20)RNAi mutants

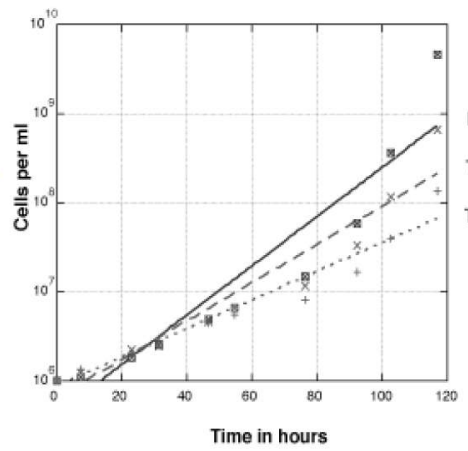

(TDDNAI1)RNAi mutants

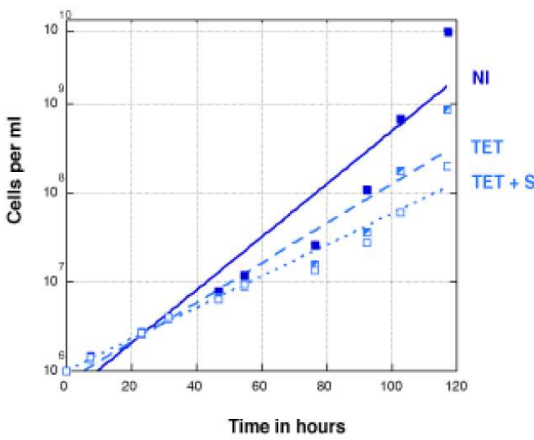

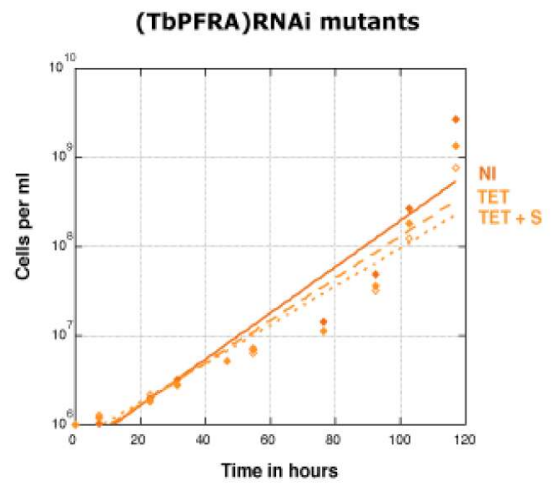

Fig.4 
A
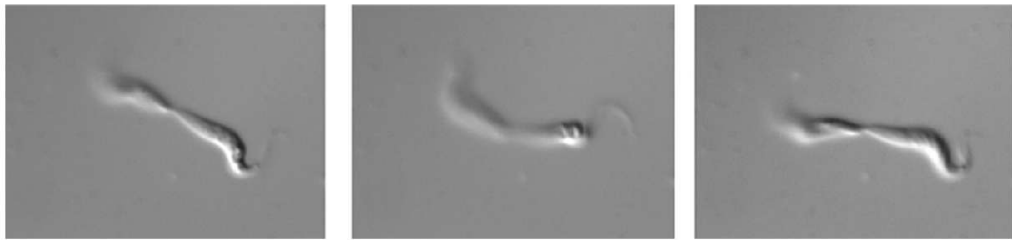

B
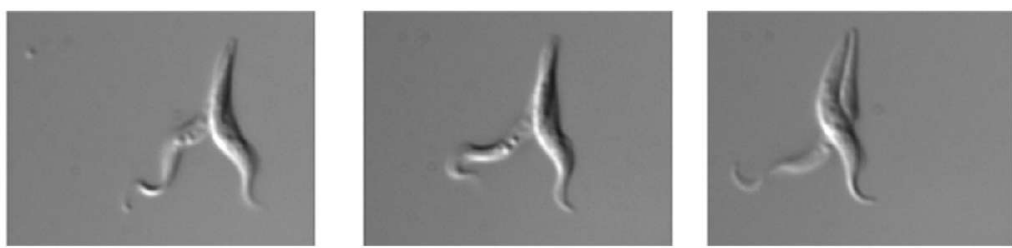

C

D
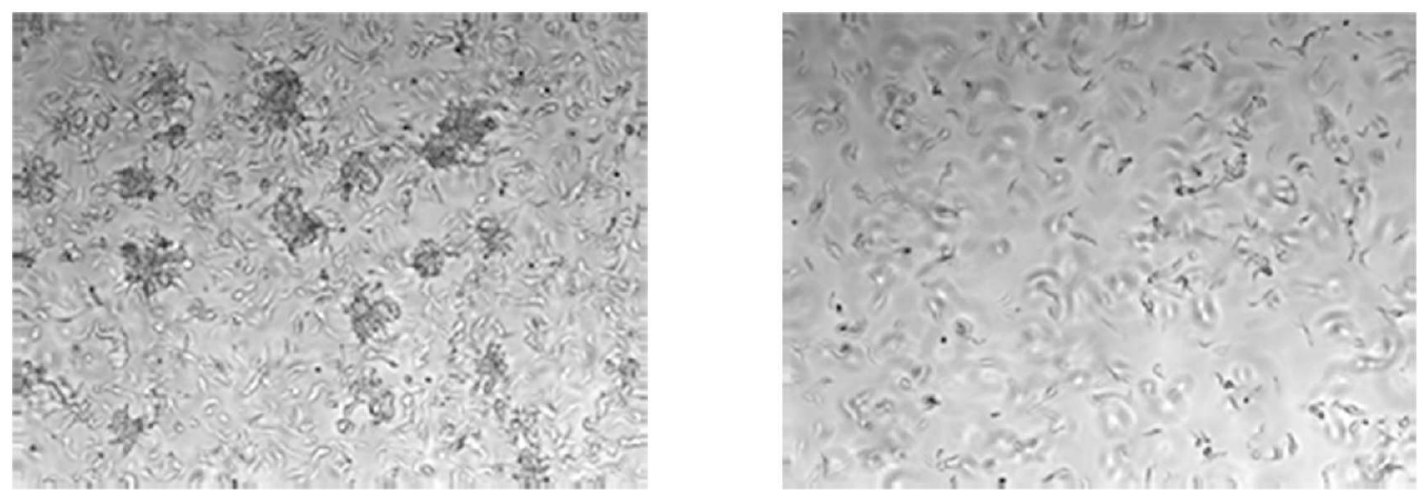

E
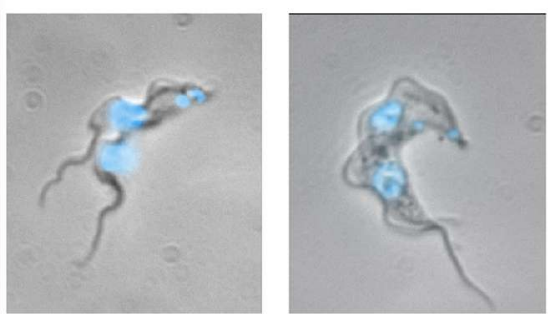

F
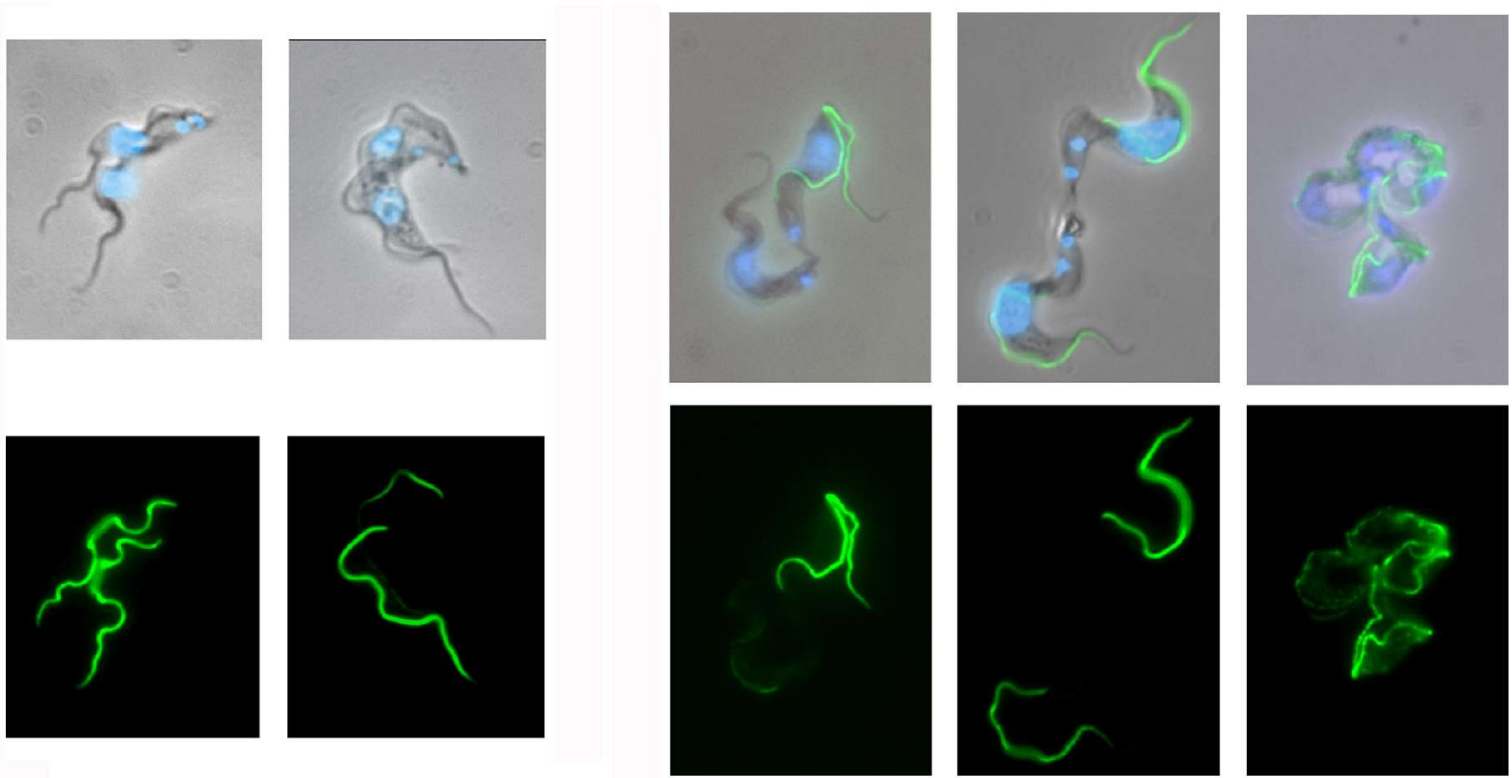

Fig. 5 